\title{
Tunneled Pleural Catheter Placement with and without Talc Poudrage for Treatment of Pleural Effusions Due to Congestive Heart Failure
}

\section{Citation}

Majid, Adnan, Fayez Kheir, Meghan Fashjian, Sumit Chatterji, Sebastian Fernandez-Bussy, Sebastian Ochoa, George Cheng, and Erik Folch. 2015. "Tunneled Pleural Catheter Placement with and Without Talc Poudrage for Treatment of Pleural Effusions Due to Congestive Heart Failure." Annals of the American Thoracic Society (November 24). doi:10.1513/ annalsats.201507-471bc.

\section{Published Version}

10.1513/annalsats.201507-471bc

\section{Permanent link}

http://nrs.harvard.edu/urn-3:HUL.InstRepos:37140366

\section{Terms of Use}

This article was downloaded from Harvard University's DASH repository, and is made available under the terms and conditions applicable to Other Posted Material, as set forth at http:// nrs.harvard.edu/urn-3:HUL.InstRepos:dash.current.terms-of-use\#LAA

\section{Share Your Story}

The Harvard community has made this article openly available. Please share how this access benefits you. Submit a story. 


\title{
Tunneled Pleural Catheter Placement with and without Talc Poudrage for Treatment of Pleural Effusions Due to Congestive Heart Failure
}

\author{
Adnan Majid ${ }^{1}$, Fayez Kheir ${ }^{2}$, Meghan Fashjian ${ }^{1}$, Sumit Chatterji ${ }^{3}$, Sebastian Fernandez-Bussy ${ }^{4}$, Sebastian Ochoa ${ }^{1}$, \\ George Cheng ${ }^{1}$, and Erik Folch ${ }^{1}$ \\ ${ }^{1}$ Division of Thoracic Surgery and Interventional Pulmonology, Beth Israel Deaconess Medical Center, Harvard Medical School, Boston, \\ Massachusetts; ${ }^{2}$ Division of Pulmonary Diseases, Critical Care, and Environmental Medicine, Tulane University Health Sciences \\ Center, New Orleans, Louisiana; ${ }^{3}$ Department of Respiratory Medicine, Addenbrooke's Hospital, Cambridge University Hospitals \\ National Health Service Trust, Cambridge, United Kingdom; and ${ }^{4}$ Section of Interventional Pulmonology, Clinica Alemana, Universidad \\ Del Desarrollo, Santiago, Chile
}

ORCID ID: 0000-0002-6203-5343 (A.M.).

\section{Abstract}

Rationale: There is a paucity of evidence regarding the role of tunneled pleural catheters in pleural effusions caused by congestive heart failure that is refractory to medical management.

Objectives: The aim of this study was to assess the feasibility of tunneled pleural catheter drainage for treatment of refractory pleural effusions associated with congestive heart failure, either when used alone or with concomitant talc pleurodesis performed during thoracoscopy.

Methods: This was a retrospective cohort study. We identified patients with congestive heart failure and recurrent symptomatic pleural effusions who were treated between 2005 and 2015 by placement of a tunneled pleural catheter. Patients underwent either thoracoscopy followed by talc poudrage and pleural catheter placement (group 1) or catheter insertion alone (group 2).
Measurements and Main Results: Forthy-three catheters were inserted in 36 patients, with 15 placed in group 1 and 28 in group 2. Successful pleurodesis was seen in $80 \%$ in group 1 and $25 \%$ in group 2 . The median time of catheter placement was 11.5 days in group 1 and 66 days in group 2. There was a significant decrease in hospital admissions and pleural interventions after catheter placement compared with before insertion $(P<0.05)$.

Conclusions: This single-center, retrospective study demonstrated the feasibility of catheter placement used alone or with talc poudrage for the treatment of refractory pleural effusions associated with congestive heart failure. The addition of talc poudrage might increase the pleurodesis rate and reduce the days to catheter removal in highly selected patients. Prospective studies on a larger number of patients are warranted to verify the safety and efficacy of this intervention.

Keywords: congestive heart failure; New York Heart Association

(Received in original form July 27, 2015; accepted in final form November 23, 2015)

Supported in part by the Thoracic Foundation (Overholt), Boston, Massachusetts.

Author Contributions: A.M. and F.K. participated in data analysis, manuscript writing, and manuscript review. M.F. participated in data collection, data analysis, and manuscript review. S.C. and S.F.-B. participated in manuscript writing and manuscript review. S.O. and G.C. participated in data collection and analysis. E.F. participated in data collection and manuscript review.

Correspondence and requests for reprints should be addressed to Adnan Majid, M.D., Director, Interventional Pulmonology, Beth Israel Deaconess Medical Center, Associate Professor of Medicine, Harvard Medical School, 185 Pilgrim Road, Deaconess-201, Boston, MA 02215. E-mail: amajid@bidmc.harvard.edu

Ann Am Thorac Soc Vol 13, No 2, pp 212-216, Feb 2016

Copyright (C) 2016 by the American Thoracic Society

DOI: 10.1513/AnnalsATS.201507-471BC

Internet address: www.atsjournals.org

Congestive heart failure $(\mathrm{CHF})$ remains the most common cause of pleural effusion. Fluid in the pleural space accumulates when increased hydrostatic pressure in the pleural microcirculation exceeds the capacity of lymphatic vessels to reabsorb the excess fluid (1). Although pleural effusion is present in approximately $70 \%$ of patients with $\mathrm{CHF}$ (2), treatment of the underlying disease usually results in fluid reabsorption.

In symptomatic patients, therapeutic thoracentesis is often considered while awaiting a pharmacological treatment effect. Occasionally, patients have recurrent symptomatic pleural effusions despite optimal medical management, or medical therapy is limited due to other complications such as low blood pressure, syncope, or worsening renal function. Available options for such patients include repeated therapeutic 
thoracentesis or drainage and pleurodesis (talc poudrage or slurry) (3-6). Alternatively, a tunneled pleural catheter can be considered in such a population (7).

Although tunneled pleural catheters are used routinely in the management of malignant pleural effusion, there are limited data demonstrating the use of these catheters in nonmalignant pleural effusions, specifically those caused by $\mathrm{CHF}$ refractory to medical management $(8,9)$. The aim of this study was to assess the feasibility of tunneled pleural catheter placement when used in this group.

\section{Methods}

\section{Study Design}

This retrospective cohort study was approved by the institutional review board with waiver of informed consent for data collection and analysis (protocol number 2014-P000258). Each patient underwent standard procedural consent for catheter placement per standard institution practices and guidelines.

\section{Subject Population and Baseline Characteristics}

Data on patients who underwent catheter (Pleur-X; CareFusion Corporation, San Diego, CA) insertion were reviewed from June 2005 until January 2015. Patients with pleural effusions due to $\mathrm{CHF}$ who had a pleural catheter inserted were included. All patients included had failed to respond to maximal medical therapy and required at least two thoracenteses within 1 month for symptomatic relief. Patients with malignancy or other confounding causes of pleural effusion such as pneumonia, postcardiac injury syndrome, or post coronary artery bypass graft were excluded from the study.

Records were reviewed for patient symptoms, demographics, cardiac history, medications, echocardiogram, serum creatinine, pleural fluid analysis, operative reports, complications after catheter placement, hospital admissions, reintervention, catheter removal date, and/or death.

Catheter infectious complications were defined as the presence of cellulitis, deep tissue infection, or pleural space infection (pus, positive pleural fluid Gram stain/culture, or positive catheter tip Gram stain/culture). Other complications recorded included: catheter occlusion, rupture, migration or malfunction due to loculations, bleeding, pneumothorax, and death directly related to the procedure. Date of removal was recorded only in patients who underwent therapeutic withdrawal of the catheter. All patients in the study were followed up to 6 month. There was no loss of follow up.

\section{Operative Techniques}

Tunneled pleural catheter inserted during medical thoracoscopy and talc poudrage (group 1). Patients underwent medical thoracoscopy (Karl Storz GmbH,

Tuttlingen, Germany) with talc poudrage followed by catheter insertion. Under ultrasound guidance, a single port was placed and rigid thoracoscopy was performed under moderate sedation in the operating room with continuous monitoring by an anesthesiologist as per standard protocols, with the patient in a lateral decubitus position. Pleural fluid was removed with a $14 \mathrm{~F}$ suction catheter and the tunneled pleural catheter was inserted and directed inferoposteriorly followed by 4 to $8 \mathrm{~g}$ of talc poudrage (mean, $5 \mathrm{~g}$ ) (Sclerosol Intrapleural Aerosol; Bryan Corporation, Woburn, MA) under direct visualization. A 24F chest tube was introduced through the thoracoscopy cannula and directed posterosuperiorly.

Both tubes were left on $-20 \mathrm{~cm} \mathrm{H}_{2} \mathrm{O}$ wall suction until combined drainage was less than $250 \mathrm{ml}$ in 24 hours. When this was achieved, the $24 \mathrm{~F}$ chest tube was removed and the catheter was capped and drained daily for 2 weeks. If pleural fluid drainage persisted for more than 2 weeks, the catheter was scheduled to be drained three times per week until it was less than $50 \mathrm{ml}$ for three consecutive drainages. When that threshold was reached, a chest ultrasound was performed, and if there was no evidence of significant pleural effusion $(>200 \mathrm{ml})$, the catheter was removed. The fluid volume was calculated by measuring the maximum perpendicular distance between the surface and the chest wall right above the diaphragm with the patient in the supine position, at maximum inspiration. If maximum perpendicular distance was less than $15 \mathrm{~mm}$ it corresponded to effusion equivalent volume of less than $200 \mathrm{ml}(10)$.

\section{Tunneled pleural catheter insertion} technique and drainage method (Group 2). Alternatively, using ultrasound, with the patient in a lateral decubitus or sitting position, a pleural fluid pocket was identified and marked. Under local anesthesia, the catheter was placed by tunneling the catheter into the subcutaneous tissue posterolaterally, approximately 6 to $8 \mathrm{~cm}$ from the marked skin insertion site. The catheter was then introduced into the pleural space using a modified Seldinger technique. Pleural fluid was removed using the catheter with dedicated prevacuumed bottles. Patients were instructed to drain the pleural cavity two to three times per week and no more than $1 \mathrm{~L}$ per session. Pleural fluid drainage was done more frequently in

Table 1. Demographics and baseline characteristics

\begin{tabular}{lccc}
\hline & Overall & Group 1 & Group 2 \\
No. of patients & & & \\
Tunneled pleural catheter inserted & 36 & 13 & 23 \\
Age, mean (range), yr & 43 & 15 & 28 \\
Female sex & $19.5(61-97)$ & $81.5(61-97)$ & $84.3(67-91)$ \\
Cardiac etiology & $19(52.7 \%)$ & $7(19.4 \%)$ & $12(33.3 \%)$ \\
$\quad$ Systolic heart failure & 13 & 3 & 10 \\
$\quad$ Diastolic heart failure & 15 & 6 & 9 \\
$\quad$ Combined heart failure & 1 & 0 & 1 \\
$\quad$ Severe pulmonary hypertension & 4 & 1 & 3 \\
Severe aortic stenosis & 3 & 0 & 3 \\
Right-sided pleural effusion & $28(78 \%)$ & $11(30.6 \%)$ & $17(47.2 \%)$ \\
Serum NT-proBNP, median, pg/ml & 3,895 & 2,780 & 4,764 \\
NYHA dyspnea score, mean & 2.49 & 2.15 & 2.67 \\
\hline
\end{tabular}

Definition of abbreviations: NT-proBNP $=\mathrm{N}$-terminal pro-brain natriuretic peptide; $\mathrm{NYHA}=\mathrm{New}$ York

Heart Association.

No. of patients

Female sex

Systolic heart failure

Diastolic heart failure

bined heart fail

Severe aortic stenosis

Right-sided pleural effusion

Serum NT-proBNP, median, $\mathrm{pg} / \mathrm{m}$ 
Table 2. Tunneled pleural catheter outcome

\begin{tabular}{lccccc}
\hline TPC No. & Pleurodesis Achieved (\%) & $\begin{array}{c}\text { TPC Placement Time }(\boldsymbol{d}) \\
\text { Median (Range) }\end{array}$ & TPC Removal (\%) & $\begin{array}{c}\text { Postintervention NYHA Score } \\
\text { Mean }\end{array}$ \\
\hline Group 1 & 15 & 80 & $11.5(2-22)$ & 80 & 1.69 \\
Group 2 & 28 & 25 & $66(31-205)$ & 25 & 1.90 \\
Overall & 43 & 44.2 & $20(2-205)$ & 44.2 & 1.82 \\
\hline
\end{tabular}

Definition of abbreviations: NYHA = New York Heart Association; TPC = tunneled pleural catheter.

group 1 for the first 2 weeks as compared with group 2.

The decision to insert the tunneled pleural catheter under ultrasound guidance or during thoracoscopy with talc poudrage was based on the patient's New York Heart Association (NYHA) dyspnea score, age, and patient preference (Table 1).

\section{Outcomes}

Successful pleurodesis in both groups was defined as no significant radiographic pleural fluid reaccumulation after catheter removal on chest radiography, chest ultrasound, or a chest computed tomography scan until the end of follow up or death that required further pleural intervention on the same side. Other reported outcomes were adverse events, number of pleural interventions, number of admissions, and serum creatinine $(6 \mathrm{mo}$ before and up to 6 mo after catheter procedure).

\section{Data Analysis and Statistical Methods} Statistical analysis was performed using SPSS version 21 , with a $P$ value of less than 0.05 defined as significant. Descriptive statistics, including mean, median, range, and percentage, were used to describe patient demographics and outcomes. Mann-Whitney test was used for continuous variables and Fisher exact test for categorical variables. Survival analysis was conducted with the Kaplan-Meier method with time to event being tunneled pleural catheter removal.

\section{Results}

A total of 43 catheters were inserted in 36 patients, including 7 patients who had subsequent contralateral catheter insertion (Table 1). Patients had a mean age of 82.5 years (range, 61-97 yr), with $52.7 \%$ being women. The median serum $\mathrm{N}$-terminal pro-brain natriuretic

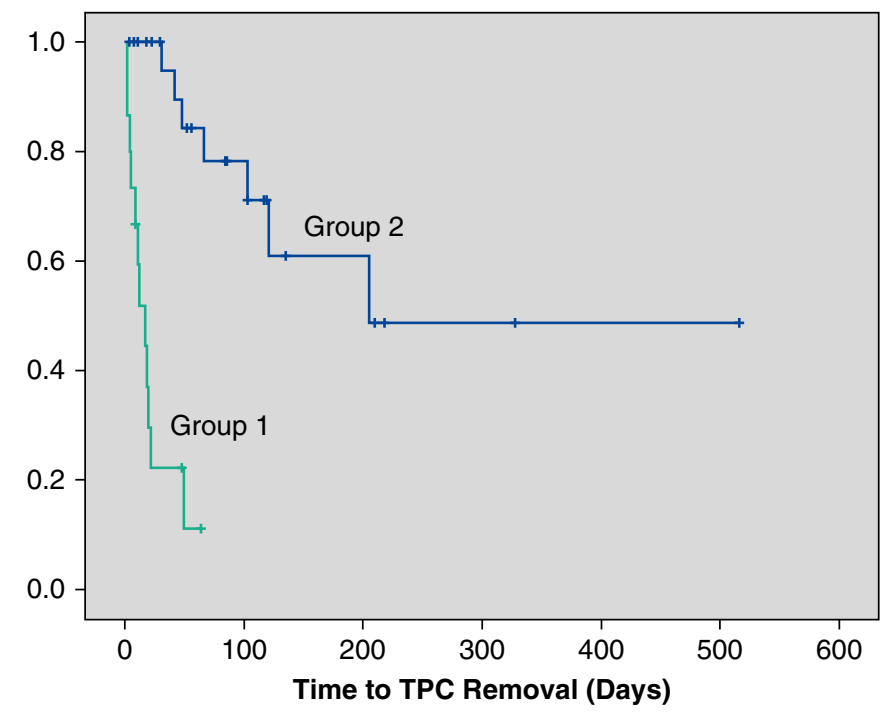

Figure 1. Time to tunneled pleural catheter (TPC) removal according to whether TPC was placed with thoracoscopy and talc poudrage (group 1) or alone (group 2). peptide level was $3,895 \mathrm{pg} / \mathrm{ml}$ (range, 668-47,742 pg/ml) before insertion of catheter. Median creatinine was $1.2 \mathrm{mg} / \mathrm{dl}$ before and after catheter insertion $(P=0.63)$. Seventy-eight percent $(28 / 36)$ of patients underwent right-sided catheter insertion. Thirteen patients (36\%) had systolic heart failure, 15 (42\%) had diastolic heart failure, 1 (3\%) had combined (systolic and diastolic) heart failure, $4(11 \%)$ had severe pulmonary hypertension, and $3(8 \%)$ had severe aortic stenosis.

\section{Treatment Outcomes Overall}

All patients reported improved dyspnea after pleural intervention. Overall, successful pleurodesis was achieved in $44.2 \%$, and catheters were removed in $44.2 \%$. After the intervention, NYHA mean score decreased from 2.49 (group $1=2.15$; group $2=2.67$ ) to 1.82 (group $1=1.69$, group $2=1.90$ ) (Table 2). Pleurodesis was achieved more frequently in group 1 (Table 2). The median time to catheter removal of all catheters (both groups) was 20 days (range, 2-205 d).

\section{Treatment Outcomes by Group}

Group 1. Fifteen catheters were inserted during thoracoscopy and talc poudrage. Median time from catheter placement to removal was 11.5 days (range, 2-22 d). Eleven successful pleurodeses were achieved initially after intervention leading to 11 catheter removals. There was one additional successful pleurodesis achieved when talc slurry was given via catheter, leading to catheter removal. This resulted in a total of 12 successful pleurodeses $(80 \%)$ and 12 catheters removed $(80 \%)$.

Group 2. Twenty-eight catheters were inserted alone under ultrasound guidance. Median time from catheter placement to removal was 66 days (range, 31-205). Seven 
Table 3. Adverse events of tunneled pleural catheters

$$
\text { Total (\%) }
$$

Group 1

Group 2

Hypotension

Cellulitis

Empyema

Parapneumonic effusion tolerate a thoracoscopy procedure. Similarly, our finding of a significantly longer time to pleural catheter removal in group 2 than in group 1 probably reflects selection bias, because patients who had lower NYHA score and/or were younger were enrolled in group 1 .

Provoking or worsening preexisting renal failure remains a major challenge in patients with CHF. Standard practice of increasing the dose of diuretics in response to worsening symptoms often leads to renal dysfunction (20). This often defines the ceiling of medical therapy and limits the extent to which symptoms may be controllable. In this study, there was no significant difference in serum creatinine 6 months before and up to 6 months after catheter insertion, suggesting that catheter drainage does not further compromise renal function in selected patients with severe $\mathrm{CHF}$.

We acknowledge several important limitations to our study. This was a retrospective cohort review without a control group (medical therapy only) or a study arm comparing chest tube and talc slurry. Although dyspnea and NYHA classification for functional limitation were recorded, there were no standardized measures of quality of life specific before or after intervention. In addition, pleural fluid drainage frequency in group 1 was more intensive as per our institutional protocol and may have contributed to the higher pleurodesis rates. Finally, as there are no evidence-based guidelines for the optimal management of this population of patients, there is an inherent referral and selection bias depending on clinician and institutional experience and preferences. Due to small number of cases per institution, there is a need for larger prospective studies to try to define optimal management strategies in this area.

In conclusion, our study adds support to the slowly enlarging corpus of data suggesting that catheter placement in selected patients with refractory pleural effusions secondary to CHF is feasible $(18,19)$. Catheter insertion with the addition of a pleural sclerosant is an approach gaining interest and is worthy of further study in this group of patients.

Author disclosures are available with the text of this article at www.atsjournals.org. 


\section{References}

1 Kinasewitz GT. Transudative effusions. Eur Respir J 1997;10:714-718.

2 Edwards JE, Race GA, Scheifley $\mathrm{CH}$. Hydrothorax in congestive heart failure. Am J Med 1957;22:83-89.

3 Freeman RK, Ascioti AJ, Dake M, Mahidhara RS. A propensitymatched comparison of pleurodesis or tunneled pleural catheter for heart failure patients with recurrent pleural effusion. Ann Thorac Surg 2014;97:1872-1876. [Discussion pp. 1876-1877.]

4 Glazer M, Berkman N, Lafair JS, Kramer MR. Successful talc slurry pleurodesis in patients with nonmalignant pleural effusion. Chest 2000;117:1404-1409.

5 Spicer AJ, Fisher JA. Recurring pleural effusion in congestive heart failure treated by pleurodesis. J Ir Med Assoc 1969;62: 177-178.

6 Davidoff D, Naparstek Y, Eliakim M. The use of pleurodesis for intractable pleural effusion due to congestive heart failure. Postgrad Med J 1983;59:330-331.

7 Srour N, Potechin R, Amjadi K. Use of indwelling pleural catheters for cardiogenic pleural effusions. Chest 2013;144:1603-1608.

8 Herlihy JP, Loyalka P, Gnananandh J, Gregoric ID, Dahlberg CG, Kar B, Delgado RM III. PleurX catheter for the management of refractory pleural effusions in congestive heart failure. Tex Heart Inst $J$ 2009;36: 38-43.

9 Chalhoub M, Harris K, Castellano M, Maroun R, Bourjeily G. The use of the PleurX catheter in the management of non-malignant pleural effusions. Chron Respir Dis 2011;8:185-191.

10 Eibenberger KL, Dock WI, Ammann ME, Dorffner R, Hörmann MF, Grabenwöger F. Quantification of pleural effusions: sonography versus radiography. Radiology 1994;191:681-684.

11 Bhatnagar R, Laskawiec-Szkonter M, Piotrowska HE, Kahan BC, Hooper CE, Davies HE, Harvey JE, Miller RF, Rahman NM, Maskell NA. Evaluating the efficacy of thoracoscopy and talc poudrage versus pleurodesis using talc slurry (TAPPS trial): protocol of an open-label randomised controlled trial. BMJ Open 2014;4: e007045.

12 Bhatnagar R, Maskell NA. Indwelling pleural catheters. Respiration 2014;88:74-85.

13 Penz ED, Mishra EK, Davies HE, Manns BJ, Miller RF, Rahman NM. Comparing cost of indwelling pleural catheter vs talc pleurodesis for malignant pleural effusion. Chest 2014;146:991-1000.

14 Ost DE, Jimenez CA, Lei X, Cantor SB, Grosu HB, Lazarus DR, Faiz SA, Bashoura L, Shannon VR, Balachandran D, et al. Quality-adjusted survival following treatment of malignant pleural effusions with indwelling pleural catheters. Chest 2014;145:1347-1356.

15 Fysh ET, Waterer GW, Kendall PA, Bremmer PR, Dina S, Geelhoed E, McCarney K, Morey S, Millward M, Musk AW, et al. Indwelling pleural catheters reduce inpatient days over pleurodesis for malignant pleural effusion. Chest 2012;142:394-400.

16 Davies HE, Mishra EK, Kahan BC, Wrightson JM, Stanton AE, Guhan A, Davies CW, Grayez J, Harrison R, Prasad A, et al. Effect of an indwelling pleural catheter vs chest tube and talc pleurodesis for relieving dyspnea in patients with malignant pleural effusion: the TIME2 randomized controlled trial. JAMA 2012;307:2383-2389.

17 DePew ZS, lqbal S, Mullon JJ, Nichols FC, Maldonado F. The role for tunneled indwelling pleural catheters in patients with persistent benign chylothorax. Am J Med Sci 2013;346:349-352.

18 Harris K, Chalhoub M. The use of a PleurX catheter in the management of recurrent benign pleural effusion: a concise review. Heart Lung Circ 2012;21:661-665.

19 Bhatnagar R, Reid ED, Corcoran JP, Bagenal JD, Pope S, Clive AO, Zahan-Evans N, Froeschle PO, West D, Rahman NM, et al. Indwelling pleural catheters for non-malignant effusions: a multicentre review of practice. Thorax 2014;69:959-961.

20 Brunner-La Rocca HP, Knackstedt C, Eurlings L, Rolny V, Krause F, Pfisterer ME, Tobler D, Rickenbacher P, Maeder MT; TIME-CHF investigators. Impact of worsening renal function related to medication in heart failure. Eur J Heart Fail 2015;17:159-168. 